OPEN ACCESS

Edited by:

Fabienne Brilot,

University of Sydney, Australia

Reviewed by:

Giuseppe Salemi,

University of Palermo, Italy

Charlotte Elisabeth Teunissen,

Vrije Universiteit

Amsterdam, Netherlands

${ }^{*}$ Correspondence:

Bibiana Bielekova

bibi.bielekova@nih.gov

Specialty section

This article was submitted to

Multiple Sclerosis and

Neuroimmunology,

a section of the journal

Frontiers in Neurology

Received: 06 September 2019 Accepted: 07 November 2019 Published: 26 November 2019

Citation:

Masvekar R, Mizrahi J, Park J, Williamson PR and Bielekova B (2019)

Quantifications of CSF Apoptotic Bodies Do Not Provide Clinical Value in Multiple Sclerosis.

Front. Neurol. 10:1241.

doi: 10.3389/fneur.2019.01241

\section{Quantifications of CSF Apoptotic Bodies Do Not Provide Clinical Value in Multiple Sclerosis}

\author{
Ruturaj Masvekar, Jordan Mizrahi, John Park, Peter R. Williamson and Bibiana Bielekova*
}

National Institute of Allergy and Infectious Diseases, National Institutes of Health, Bethesda, MD, United States

Multiple sclerosis (MS) is an inflammatory disease of the central nervous system (CNS) that leads to the death of neurons and oligodendrocytes, which cannot be measured in living subjects. Physiological cellular death, otherwise known as apoptosis, progresses through a series of stages which culminates in the discharge of cellular contents into vesicles known as apoptotic bodies (ABs) or apoptosomes. These ABs can be detected in bodily fluids as Annexin-V-positive vesicles of $0.5-4.0 \mu \mathrm{m}$ in size. In addition, the origin of these ABs might be detected by staining for cell-specific surface markers. Thus, we investigated whether quantifications of the total and CNS cell-specific ABs in the cerebrospinal fluid (CSF) of patients provided any clinical value in MS. Extracellular vesicles, from CSF of 64 prospectively-acquired subjects, were collected in a blinded fashion using ultra-centrifugation. ABs were detected by flow cytometry using bead-enabled size-gating and Annexin-V-staining. The origin of these ABs was further classified by staining the vesicles for cell-specific surface markers. Upon unblinding, we evaluated the differences between diagnostic categories and correlations with clinical measures. There were no statistically significant differences in the numbers of total or any cell-specific ABs across different disease diagnostic subgroups and no significant correlations with any of the tested clinical measures of CNS tissue destruction, disability, MS activity, and severity (i.e., rates of disability accumulation). Overlap of cell surface markers suggests inability to reliably determine origin of ABs using antibody-based flow cytometry. These negative data suggest that CNS cells in MS either die by non-apoptotic mechanisms or die in frequencies indistinguishable by current assays from apoptosis of other cells, such as immune cells performing immunosurveillance in healthy conditions.

Keywords: multiple sclerosis, cerebrospinal fluid, apoptotic bodies, clinical outcomes, flow cytometry, cell surface markers

\section{INTRODUCTION}

Multiple sclerosis (MS) is a chronic immune-mediated disease of the central nervous system (CNS), leading to the demyelination of axons and neurodegeneration. Alongside traumatic brain injury, it is the most frequent cause of neurological disability in young adults (1). Findings from prior studies led to the hypothesis that MS can be largely divided into two stages, starting with the inflammatory phase in the periphery and later entering into the neurodegenerative phase (2). Although great progress has been made in understanding the inflammatory components of the disease, the neurodegenerative components are still obscure. 
Currently, there are two main ways to measure neurodegenerative process in living human subjects: structural imaging and measurement of neurofilament light chain protein (NFL) (3, 4). Structural (MRI) imaging identifies CNS tissue destruction as brain/spinal cord atrophy. However, MRI imaging fails to provide cellular or molecular information and therefore cannot reliably measure the loss of crucial cell types such as neurons and oligodendrocytes, especially when loss of these CNS cells may be masked by infiltration of CNS tissue by immune cells or by compensatory astrogliosis. With emergence of ultra-sensitive Single Molecule Analysis (Simoa) NFL assay $(5,6)$ blood (serum or plasma) NFL levels can be measured both in healthy subjects and MS patients. In MS NFL levels are increased during MS activity and they can weakly predict subsequent MS progression on a group, but not individual levels $(4,7-11)$. Thus, there is still a need to develop biomarkers of neuronal and oligodendroglial injury/loss that can be applied on a patient level.

Pathology studies have shown the presence of apoptotic cells, mainly oligodendrocytes and neurons, at the site of MS lesions (2, 12, 13), suggesting that CNS cell apoptosis plays an important role in the irreversible neurological disability during the progressive stage of MS. This hypothesis was further supported by animal modeling with antiapoptotic protein Bcell lymphoma-2 (Bcl-2)-overexpressing transgenic mice; in comparison with wild type (WT) these transgenic mice showed reduced experimental autoimmune encephalomyelitis (EAE)severity, despite similar inflammatory response (14).

Apoptotic cells progress through a series of stages including chromatin condensation, DNA fragmentation, membrane blebbing, and cell shrinkage, which all culminate in the discharge of cellular contents into extracellular vesicles, known as apoptotic bodies (ABs) or apoptosomes $(15,16)$. Previous studies have tried to isolate and identify ABs from subject's body fluid and use them as markers of respective disease-related degenerative processes (17-20).

Thus, the goal of the current study was to identify the presence of apoptotic cells in the CNS of living subjects by measuring the total and cell-specific ABs in cerebrospinal fluid (CSF) of patients. Additionally, we asked whether densities of total or cellspecific ABs differentiate MS from healthy donors (HDs), and within MS patient cohorts correlate with clinical measures of CNS tissue destruction, disability, MS activity and severity (i.e., rates of disability accumulation).

\section{MATERIALS AND METHODS \\ Cell Cultures and Treatments}

Human neuroblastoma cells (SK-N-SH; ATCC\# HTB-11, Manassas, VA) were cultured on poly-L-lysine (PLL; SigmaAldrich, St. Louis, MO) -coated plates (Costar, Corning, $\mathrm{NY}$ ), in Dulbecco's modified Eagles medium (DMEM; Gibco, Gaithersburg, MD) supplemented with fetal bovine serum (FBS; Gemini Bio-Products, Sacramento, CA), and sodium pyruvate (Lonza, Walkersville, MD). Cells were either left untreated (Control) or treated with Staurosporine $(0.5 \mu \mathrm{M}$; R\&D Systems Inc., Minneapolis, MN). Twenty four hours after treatment, culture supernatants were collected and stored on ice until further use. Cells were washed with phosphate-buffered saline (PBS; Gibco, Gaithersburg, MD) and detached from plate using

TABLE 1 | Subjects' demographics data based on their disease diagnosis.

\begin{tabular}{|c|c|c|c|c|c|c|c|}
\hline & Diagnosis & HD & NIND & OIND & CIS & RR-MS & P-MS \\
\hline N & Female/male & $4 / 6$ & $1 / 4$ & $0 / 12$ & $2 / 0$ & $11 / 6$ & $11 / 7$ \\
\hline \multirow[t]{3}{*}{ Age } & Average & 43.8 & 42.2 & 56.8 & 53.3 & 46.2 & 60.6 \\
\hline & SD & 12.1 & 13.1 & 13.3 & 6.1 & 10.3 & 6.0 \\
\hline & Range & 24.3-60.5 & $26.4-60.3$ & $24.5-70.0$ & $48.9-57.6$ & $24.2-66.5$ & $49.9-70.0$ \\
\hline Clinical disease activity & Active/non-active & NA & NA & NA & NA & $4 / 13$ & $2 / 16$ \\
\hline COMRIS-CTD & Range & NA & NA & NA & NA & $2.2-24.2$ & $1.5-25.1$ \\
\hline \multirow[t]{3}{*}{ EDSS } & Average & NA & NA & NA & NA & 2.4 & 5.3 \\
\hline & SD & NA & NA & NA & NA & 1.6 & 1.8 \\
\hline & Range & NA & NA & NA & NA & $1.0-6.5$ & $2.5-7.5$ \\
\hline CombiWISE & Average & NA & NA & NA & NA & 20.5 & 43.7 \\
\hline \multirow{2}{*}{ MS-DSS } & SD & NA & NA & NA & NA & 0.8 & 1.0 \\
\hline & Range & NA & NA & NA & NA & $0.5-3.4$ & $0.5-4.0$ \\
\hline \multirow[t]{3}{*}{ CombiWISE slope } & Average & NA & NA & NA & NA & 1.7 & 1.9 \\
\hline & SD & NA & NA & NA & NA & 1.5 & 1.5 \\
\hline & Range & NA & NA & NA & NA & $-1.2-4.6$ & $-1.1-4.3$ \\
\hline
\end{tabular}


trypsin-EDTA solution (Sigma-Aldrich); detached cells were pelleted and stored on ice until further use.

\section{CSF Collection and Processing}

All subjects were recruited under IRB-approved protocols (Comprehensive Multimodal Analysis of Neuroimmunological Diseases of the Central Nervous System, ClinicalTrials.gov Identifier: NCT00794352; and Evaluation and Follow-up of Patients with Cryptococcosis, ClinicalTrials.gov Identifier: NCT00001352) and all patients provided written informed consent. CSF from subjects were collected per standardized operating procedures (21). CSF aliquots were prospectively labeled using alphanumeric code, stored on ice until further use and analyzed in a blinded fashion.

\section{Isolation of Apoptotic Bodies}

$\mathrm{ABs}$ were isolated from culture supernatants and CSF as previously described $(19,22-24)$. Briefly, cells were isolated and removed by pelleting at $335 \mathrm{~g}$ for $10 \mathrm{~min}$. To remove cell-debris, cell-free supernatants were centrifuged at $1,000 \mathrm{~g}$ for $10 \mathrm{~min}$; followed by another centrifugation at 2,000 $\mathrm{g}$ for $30 \mathrm{~min}$ to pellet ABs. Pelleted ABs were resuspended and washed with PBS.

\section{Flow Cytometry}

ABs were stained with Annexin V-FITC, and cells were stained with Annexin V-FITC and Propidium Iodide (TACS ${ }^{\circledR}$ Annexin V Kit; Trevigen Inc., Gaithersburg, MD) as per manufacturer's instructions. CSF ABs were also stained for CNS cell-specific surface markers to identify their origin: We used cell-surface markers previously employed in isolation of human CNS cells from brain specimens using immune-panning, and validated by cell-specific RNA profiles $(25,26)$ : CD90 (Neuronal surface marker; Human CD90/Thy1 APC-conjugated Antibody; R\&D Systems, Minneapolis, MN; Clone \# Thy-1A1), HepaCAM (Astroglial surface marker; Human HepaCAM Antibody; R\&D Systems; Clone \# 419305; tagged with DyLight 405; Novus Biologicals, Centennial, CO), GalC (Oligodendroglial surface
A

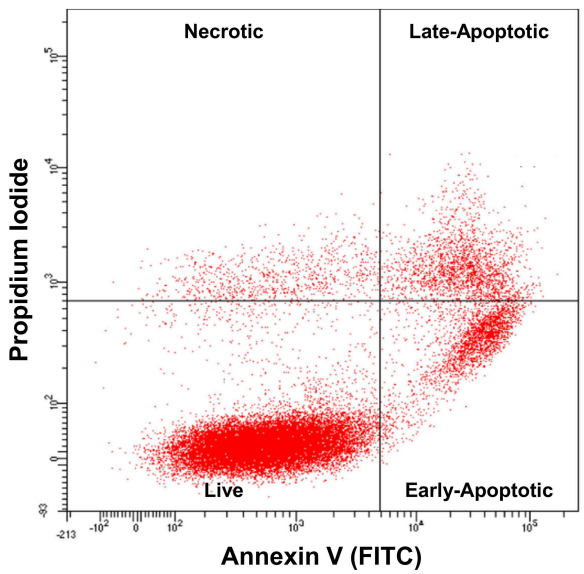

Staurosporine

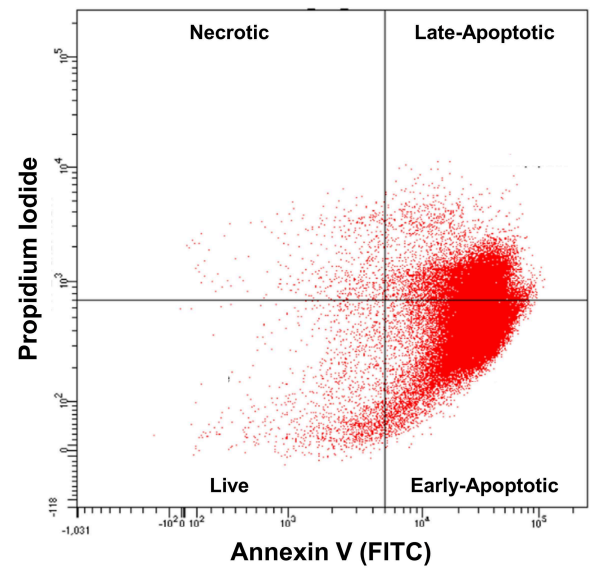

B

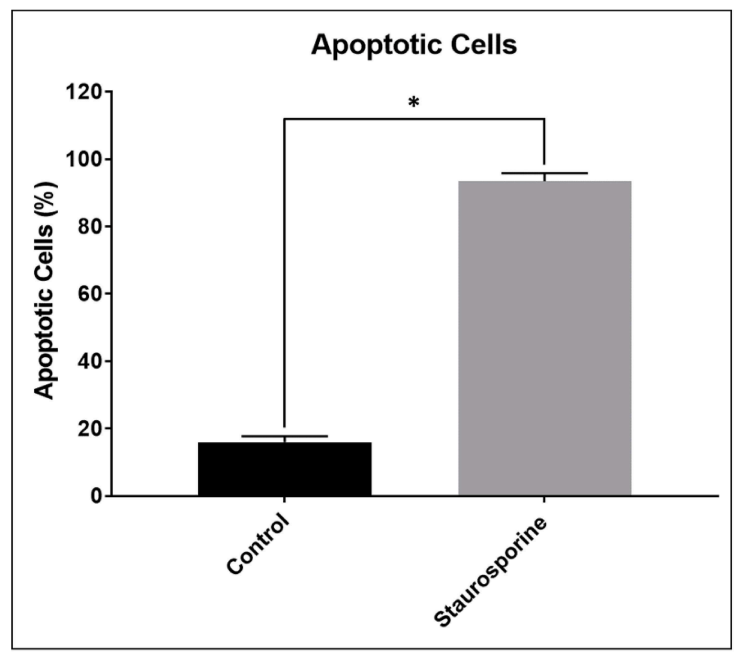

FIGURE 1 | (A) Representative flow cytometry images of cells stained with Annexin V-FITC and propidium iodide after control or Staurosporine (0.5 $\mu$ M) treatment for 24h. (B) Plot of apoptotic cells (\%). The error bars represent standard deviation $(n=6)$; data were analyzed using Wilcoxon test, $P=0.031 .{ }^{*} p<0.05$. 
marker; Anti-Galactocerebroside Antibody; EMD Millipore, Burlington, MA; Clone \# mGalC; tagged with PerCP-Cy5.5; Novus Biologicals), CD31 (Endothelial cell surface marker
(27); Human CD31/PECAM-1 PE-conjugated Antibody; R\&D Systems; Clone \# 9G11), and CD14 (Myeloid lineage cell surface marker (28); Alexa Fluor ${ }^{\circledR} 700$ anti-human CD14 Antibody;

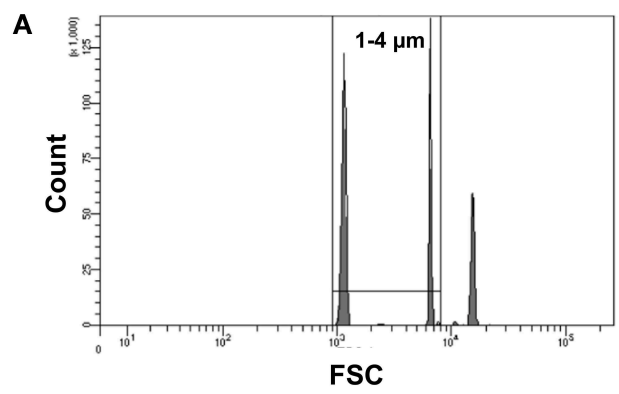

B

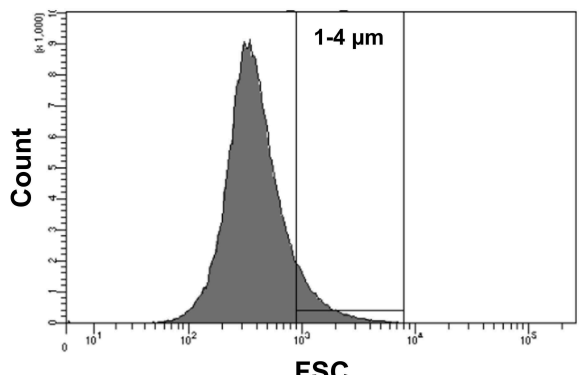

Control

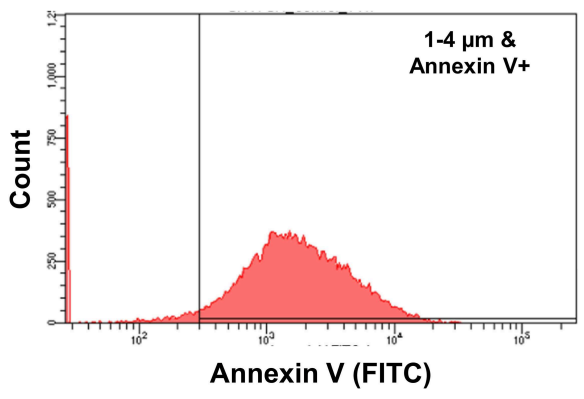

Staurosporine

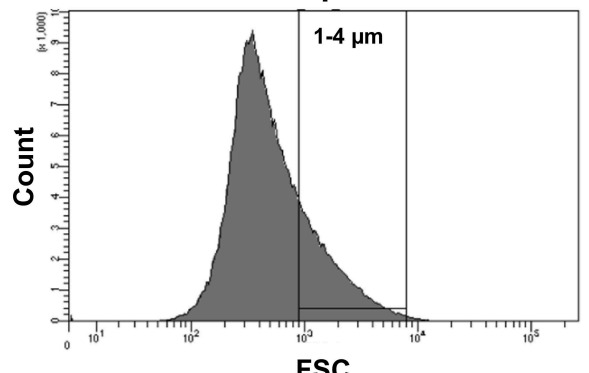

FSC

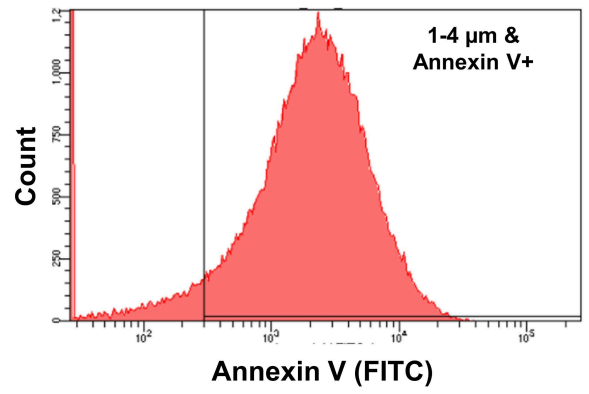

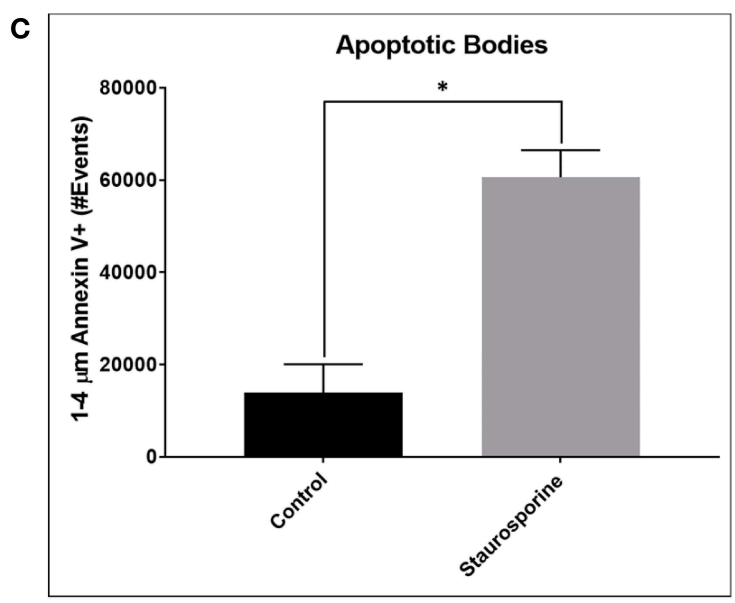

FIGURE 2 | (A) Flow cytometry images of size calibration beads (1, 4, and $6 \mu \mathrm{m}$ beads). (B) Representative flow cytometry images indicating process of ABs identification using size gate $(1-4 \mu \mathrm{m})$ and Annexin V-FITC staining, from cell culture supernatants after control or Staurosporine $(0.5 \mu \mathrm{M})$ treatment. (C) Plot of ABs (1-4 $\mu \mathrm{m}$ and Annexin V-positive events). The error bars represent standard deviation $(n=6)$; data were analyzed using Wilcoxon test, $P=0.031 .{ }^{*} p<0.05$. 
BioLegend, San Diego, CA; Clone \# HCD14). Briefly, after wash with PBS, pelleted ABs were resuspended in Annexin V-FITC and fluorescence-tagged antibodies against cell-specific surface markers in Annexin V-binding buffer (provided with TACS ${ }^{\circledR}$ Annexin $\mathrm{V}$ Kit) and incubated in dark for $15 \mathrm{~min}$ at room temperature. Stained ABs were washed with binding buffer and then analyzed using fluorescence-activated flow cytometer (BD LSR II Flow Cytometer, BD Biosciences, San Jose, CA). Gating on ABs included size gate [1-4 $\mu \mathrm{m}$ (29)], using Flow Cytometry Size Calibration Kit (ThermoFisher Scientific, Grand Island, NY). The vesicles in 1-4 $\mu \mathrm{m}$ size gate were further analyzed for Annexin V and cell-specific surface markers' staining.

\section{Subjects' Demographics Data}

A total of 64 CSF samples were analyzed. After unblinding diagnostic codes, this cohort consisted of healthy donors (HD, $n=10$ ), non-inflammatory neurological disorders (NIND, $n$ $=5$ ), other inflammatory neurological disorders (OIND, $n=$ 12; mainly, comprised of Cryptococcal Meningitis patients), clinically isolated syndrome that did not yet fulfill MS diagnostic criteria (CIS, $n=2$ ), relapsing-remitting MS (RR-MS, $n=17$ ), and progressive MS [P-MS, comprised of both secondary- (SPMS) and primary-progressive MS (PP-MS), $n=18$ ] (Table 1). MS diagnostic subgroups (CIS, RR-MS, SP-MS, and PP-MS) were classified using McDonald's criteria, 2010 revisions (30). MS cohort (both RR- and P-MS) was further separated based on disease activity (active vs. non-active MS) using clinical relapses and new contrast-enhancing or new MRI lesions.

\section{Statistical Analyses}

ABs data for subjects' CSF samples were acquired with the operator blinded to subjects' clinical diagnoses. After data acquisition for all subjects, ABs per $\mathrm{ml}$ of CSF were compared across disease diagnostic subgroups (HD, NIND, OIND, RR-MS, and P-MS) using one-way ANOVA; as we have acquired CSF samples from only two CIS subjects, they were not included in analyses. Also, within MS subjects, ABs per $\mathrm{ml}$ of CSF were compared across disease activity (active vs. non-active
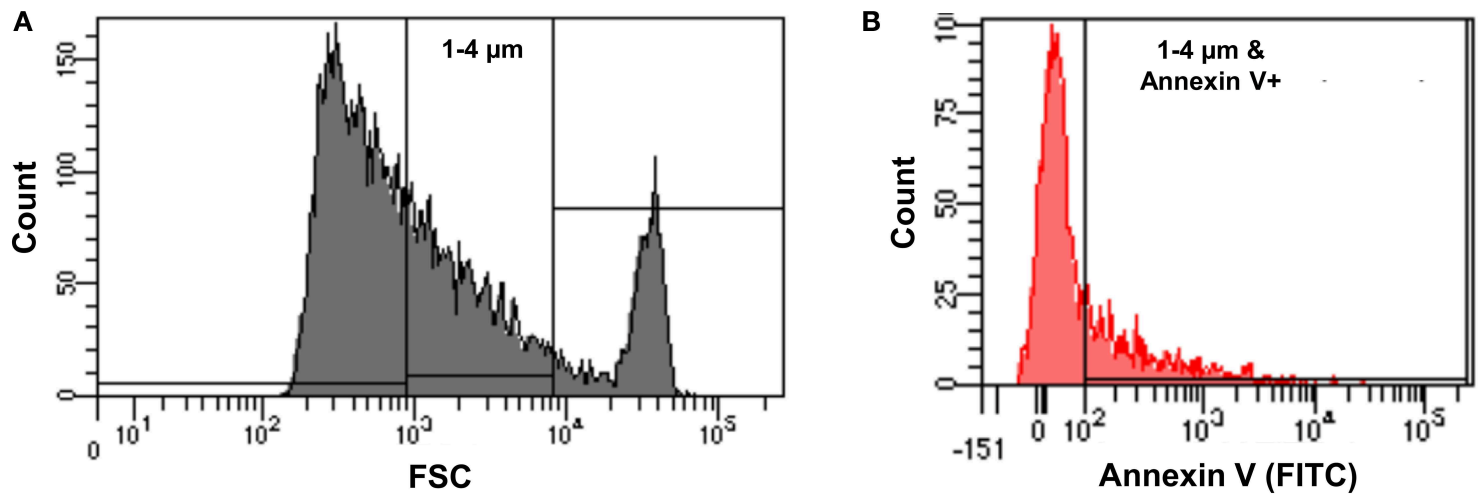

C
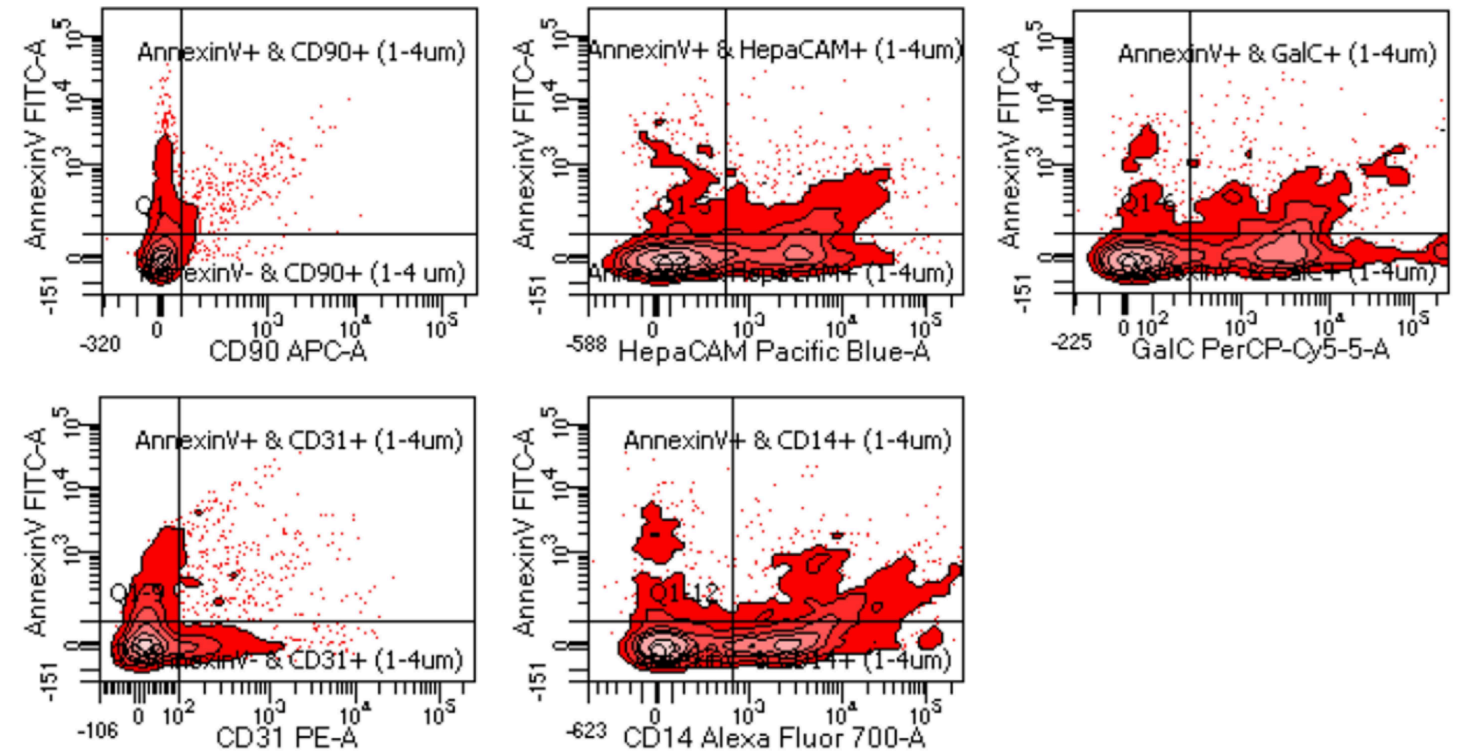

FIGURE 3 | (A) Representative flow cytometry image indicating how size gate was used to select 1-4 $\mu \mathrm{m}$ vesicles from patients' CSF samples. (B) Representative flow cytometry image showing process of identification of ABs from 1 to $4 \mu \mathrm{m}$ sized vesicles using Annexin V-FITC staining (1-4 $\mu \mathrm{m}$ and Annexin V-positive events). (C) Representative flow cytometry images showing how origin of ABs was identified using CNS cell-specific surface markers staining. 
MS) using non-parametric (Mann-Whitney) test. Within MS subjects, ABs per $\mathrm{ml}$ of CSF were correlated with machinelearning-optimized clinical and imaging measures of CNS tissue destruction [Composite MRI scale of CNS tissue destruction, COMRIS-CTD (31)], disability [Expanded Disability Status Scale, EDSS (32) and Combinatorial Weight-Adjusted Disability
Scale, CombiWISE (33)], severity [Multiple Sclerosis Disease Severity Scale, MS-DSS (34)], and disability progression slopes (CombiWISE Slope) derived from linear regression models from CombiWISE measurements during longitudinal follow-up after LP collection using Spearman correlation analysis (GraphPad Prism 7; GraphPad Software Inc., La Jolla, CA).
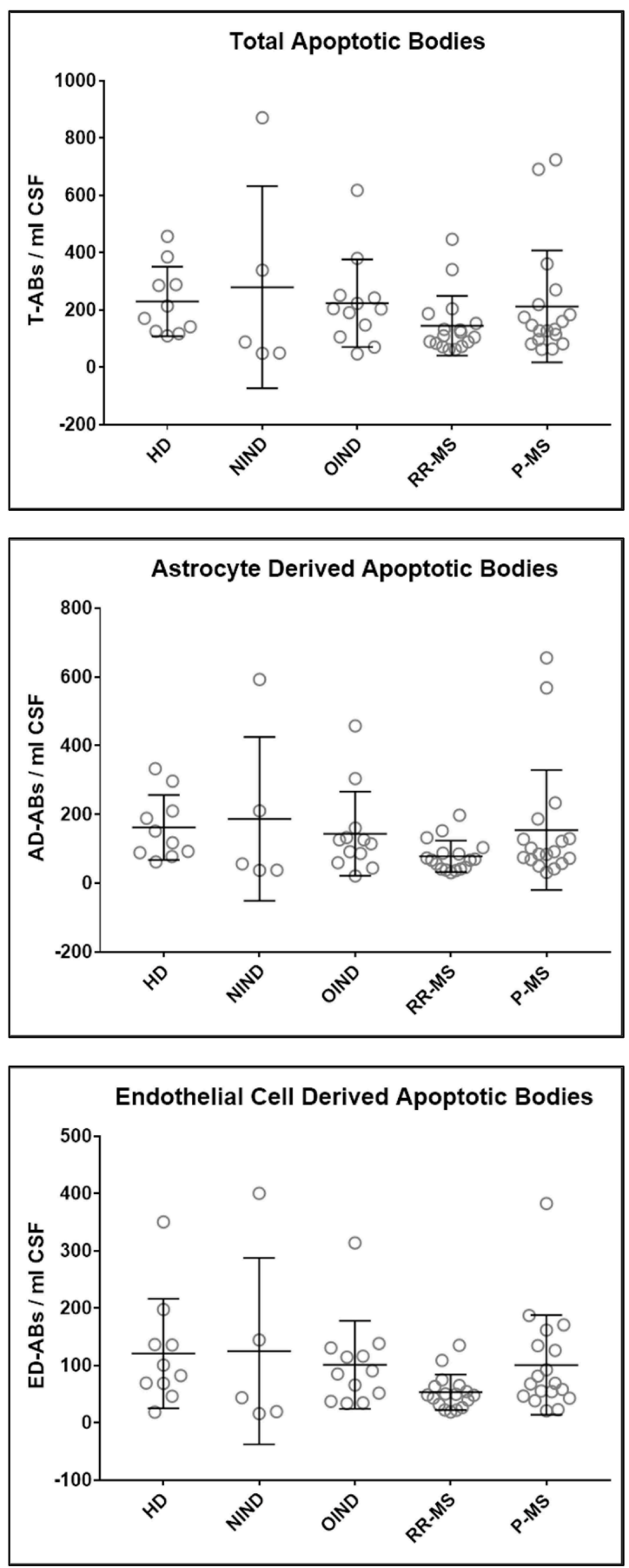
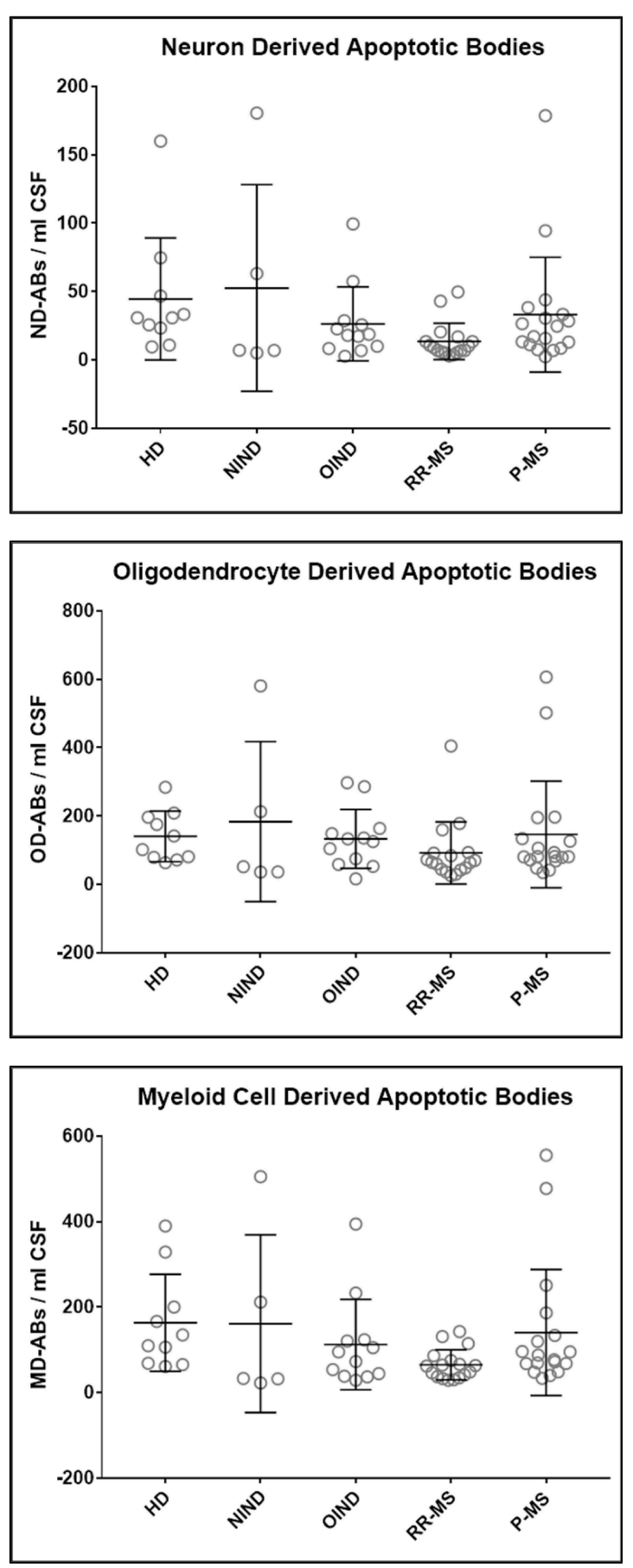

FIGURE 4 | Plots of total and CNS cell-specific ABs adjusted for CSF volume (ABs/ml CSF). Each point represents individual subject; and error bars represent standard deviation $(n: \mathrm{HD}=10, \mathrm{NIND}=5, \mathrm{OIND}=12, \mathrm{RR}-\mathrm{MS}=17$, and P-MS $=18$ ); data were analyzed using one-way ANOVA. 
Masvekar et al.

Quantification of CSF ABs

RESULTS

In vitro Model Validation

We validated our "identification and assessment of Abs" model using human neuronal cell line (SK-N-SH) cultures. As a positive control for induction of apoptosis we used Staurosporine treatment $(0.5 \mu \mathrm{M}, 24 \mathrm{~h})$. Apoptotic cells were identified by staining with Annexin V and PI and were analyzed using flow cytometry. According to manufacturer's (TACS ${ }^{\circledR}$ Annexin V Kit) instructions both Annexin V and PI-negative cells are live, only Annexin V-positive cells are early-apoptotic, both Annexin Vand PI-positive cells are late-apoptotic and only PI-positive cells are necrotic (Figure 1A). After Staurosporine treatment, the \% of apoptotic cells was significantly elevated (Figure 1B).
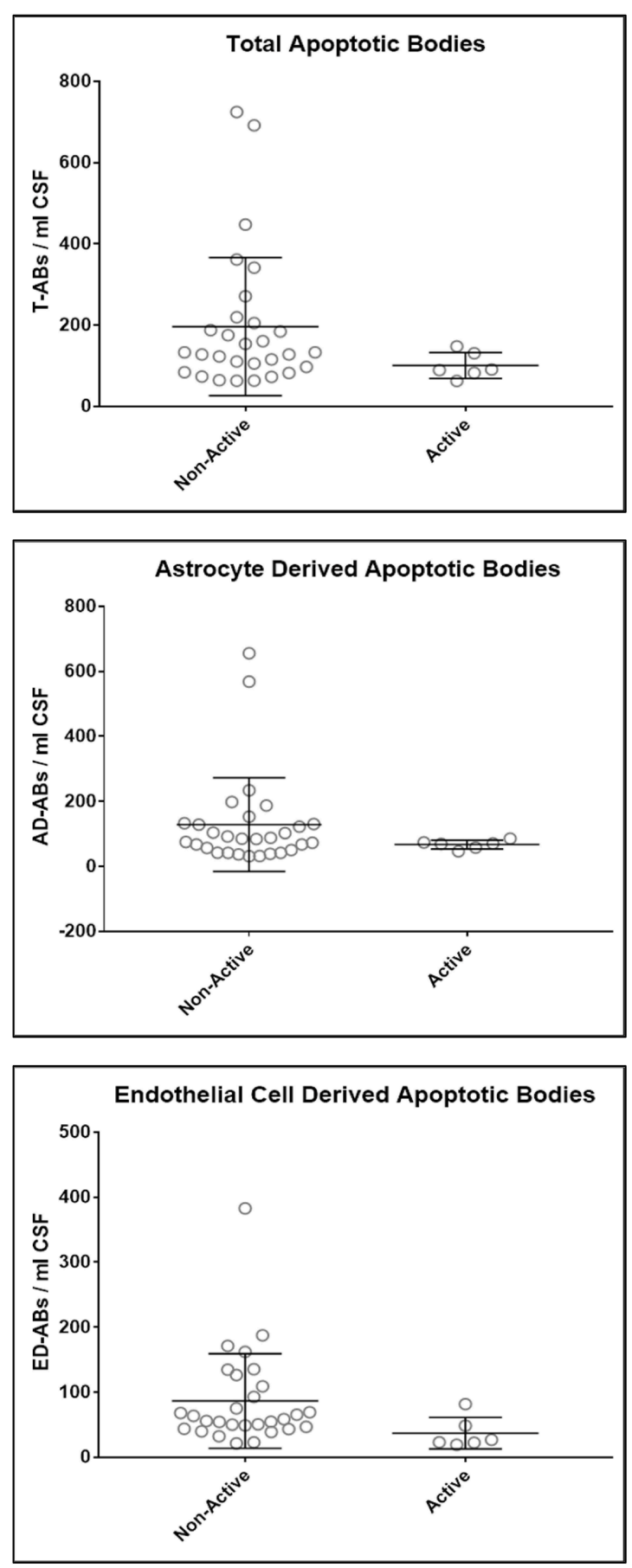
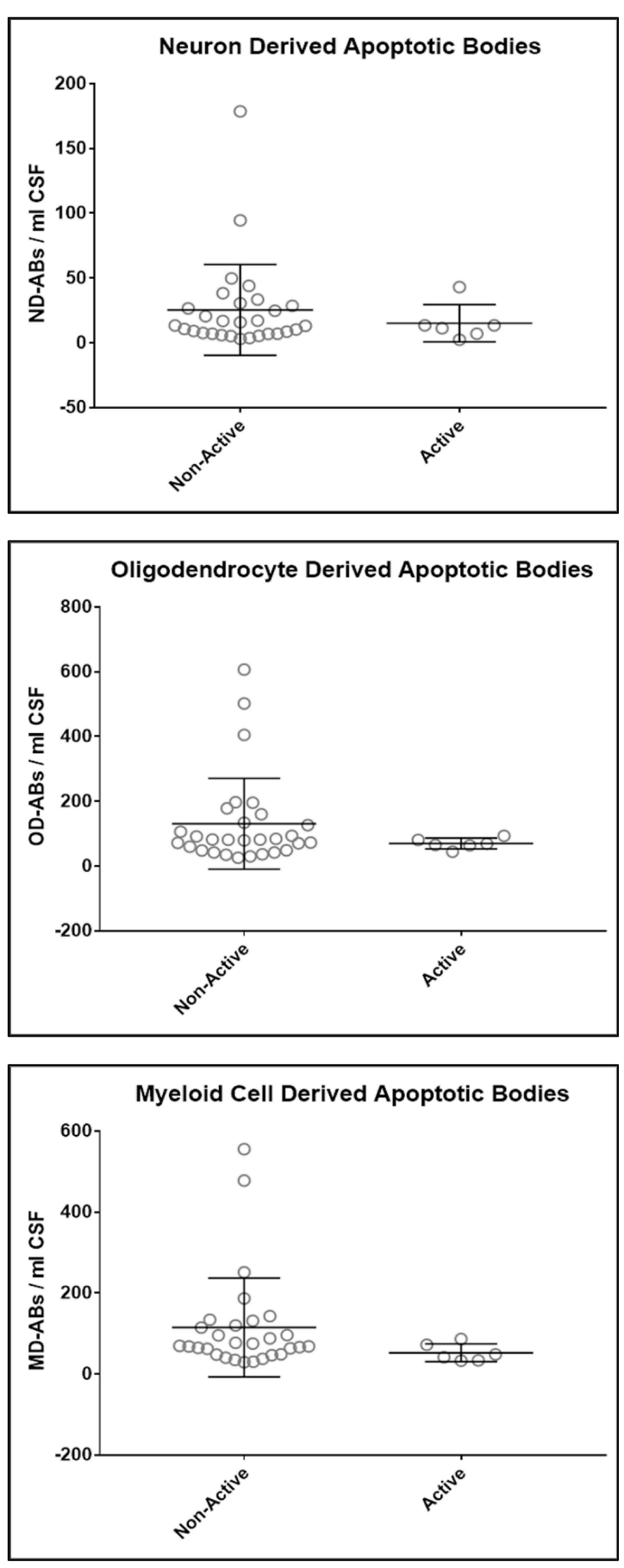

FIGURE 5 | Plots of total and CNS cell-specific ABs adjusted for CSF volume (ABs/ml CSF). Each point represents individual MS subject; and error bars represent standard deviation ( $n$ : nonactive $\mathrm{MS}=29$ and Active MS =6); data were analyzed using nonparametric (Mann-Whitney) test.

Frontiers in Neurology | www.frontiersin.org

7

November 2019 | Volume 10 | Article 1241 
Quantifying the induction of apoptosis by Staurosporine in our culture conditions, we next sought to quantify ABs in cell culture supernatants in order to demonstrate that our assay could differentiate between the release of ABs from control and Staurosporine-treated cultures. To this end, size gates [1-4 $\mu \mathrm{m}$, an average size of ABs (29)] were applied in combination with Annexin V staining. First, 1-4 $\mu \mathrm{m}$ size gates were set using 1, 4 , and $6 \mu \mathrm{m}$ beads (Figure 2A; Flow Cytometry Size Calibration Kit, ThermoFisher Scientific). Within $1-4 \mu \mathrm{m}$ vesicles $A B s$ were identified as Annexin $\mathrm{V}$ positive (Figure 2B). Total ABs were quantified (1-4 $\mu \mathrm{m}$ and Annexin V-positive events); after Staurosporine treatment the total number of $\mathrm{ABs}$ in cell culture supernatants were significantly elevated (Figure 2C).

\section{Analyses of CSF Apoptotic Bodies}

Verifying the flow-cytometry-based ABs detection in cell culture supernatants, we next applied the same assay to prospectivelyacquired CSF samples. As described in the methods, extracellular vesicles were collected using the differential centrifugation approach. 1-4 $\mu \mathrm{m}$ vesicles were selected using size gate set by known sized beads (Figure 3A). From these vesicles total ABs were detected using Annexin V staining (1-4 $\mu \mathrm{m}$ and Annexin V-positive events; Figure 3B).

While total number of $\mathrm{ABs}$ in the CSF may be clinically useful, we considered the possibility that apoptosis occurs in the intrathecal compartment also under physiological conditions: e.g., any activated immune cell may cross the blood brain barrier as a part of active immunosurveillance mechanism. Such immune cell (e.g., T lymphocyte), if not re-activated in the CNS compartment, may either re-cycle back to blood via lymphatic system, or undergo apoptosis as part of physiological termination of the immune response $(35,36)$. Thus, we envisioned that the assay that could identify the cellular origin of $\mathrm{ABs}$ may have significantly higher clinical utility. To this end, we employed fluorescently-tagged antibodies specific for surface markers of different CNS cells. Selected surface markers/antibodies were previously validated as CNS cell-types-specific, because they were used to isolate specific CNS cells (i.e., neurons, oligodendrocytes, astrocytes, microglia, and endothelial cells) from human brain samples via immunopanning. Subsequent sequencing of thus-isolated CNS cell types validated that expected cellspecific transcripts were only expressed in appropriate CNS cell-type $(25,26)$.

The utilized cell-specific markers were: CD90+ ABs (neurons derived ABs), HepaCAM+ ABs (astrocytes derived ABs), GalC+ $\mathrm{ABs}$ (oligodendrocytes derived ABs), $\mathrm{CD} 31+\mathrm{ABs}$ (endothelial cells derived $\mathrm{ABs}$ ), and $\mathrm{CD} 14+\mathrm{ABs}$ (myeloid cells derived ABs) (Figure 3C). Total number of $\mathrm{ABs}$ and cell-specific $\mathrm{ABs}$ were adjusted for CSF volume to obtain the number of $\mathrm{ABs}$ per $\mathrm{ml}$ of CSF (ABs/ml).

Upon unblinding the diagnostic categories, we observed no statistically significant differences in number of total as well as CNS cell-specific ABs across disease diagnostic subgroups or MS activity (Figures 4, 5). However, while using non-overlapping cell-surface markers (i.e., each selected cell surface marker is specific for one CNS cell type and should not be expressed on any other CNS cells), we observed substantial co-expression of these markers on individual ABs. This overlap could be quantified by how much the sum of cell-specific ABs exceeds total ABs (Figure 4 and Supplementary Data File 1). Because the sum of cell-specific $A B s$ always exceeded total number of $A B s$, we conclude that ABs most likely exhibited non-specific binding of antibodies. High non-specific antibody binding is a well-known problem affecting apoptotic cells, as apoptosis-induced changes in plasma cell membrane upregulate "eat me" signals recognized by phagocytes, including enhanced, non-specific binding of antibodies (37-39).

Consequently, we observed no correlations between the numbers/concentrations of total or any cell-specific ABs with accurate clinical and imaging measures CNS tissue destruction, disability, MS severity, and disability progression (Table 2).

\section{DISCUSSION}

MS has been studied extensively regarding the inflammatory component of disease (40). However, neurodegenerative component of MS, or immune-mediated destruction of specific CNS cells cannot be measured in living subjects. In this study, we attempted to analyze apoptosis in living subjects by assessing $\mathrm{ABs}$ in CSF. While there have been previous attempts to

TABLE 2 | Correlation analysis (Spearman $r$ and $P$-values) between adjusted total (T-ABs) and CNS cell-specific ABs (ND-ABs, neurons; AD-ABs, astrocytes; OD-ABs, oligodendrocytes; ED-ABs, endothelial cells; and MD-Abs, myeloid cells) in subjects' CSF (ABs/ml CSF) and their clinical measures of CNS tissue destruction, disability, and severity.

\begin{tabular}{|c|c|c|c|c|c|c|c|}
\hline & & T-ABs & ND-ABs & AD-ABs & OD-ABs & ED-ABs & MD-ABs \\
\hline \multirow[t]{2}{*}{ COMRIS-CTD } & Spearman $r$ & -0.20 & -0.02 & -0.10 & -0.13 & -0.19 & -0.08 \\
\hline & $P$-value & 0.25 & 0.89 & 0.57 & 0.46 & 0.26 & 0.66 \\
\hline \multirow[t]{2}{*}{ EDSS } & Spearman $r$ & -0.07 & 0.23 & 0.07 & 0.01 & 0.07 & 0.15 \\
\hline & $P$-value & 0.69 & 0.19 & 0.70 & 0.97 & 0.68 & 0.38 \\
\hline \multirow[t]{2}{*}{ CombiWISE } & Spearman $r$ & -0.11 & 0.25 & 0.07 & 0.02 & 0.00 & 0.13 \\
\hline & $P$-value & 0.53 & 0.14 & 0.68 & 0.92 & 0.99 & 0.45 \\
\hline \multirow[t]{2}{*}{ MS-DSS } & Spearman $r$ & -0.18 & 0.04 & -0.08 & -0.09 & -0.13 & -0.04 \\
\hline & $P$-value & 0.29 & 0.84 & 0.64 & 0.63 & 0.44 & 0.82 \\
\hline \multirow[t]{2}{*}{ CombiWISE slope } & Spearman $r$ & -0.29 & 0.05 & -0.05 & -0.08 & -0.30 & -0.08 \\
\hline & $P$-value & 0.09 & 0.80 & 0.76 & 0.64 & 0.08 & 0.65 \\
\hline
\end{tabular}


analyze blood/serum extracellular vesicles as markers of CNS disorders (41-43), there is no evidence for the presence of CNS ABs in blood/serum; this is likely due to their large size $(0.5-4 \mu \mathrm{m})(16,24,29,44)$ which prevents ABs from crossing the blood brain barrier (BBB) or their rapid elimination from the blood by the splenic or hepatic reticulo-endothelial system. Moreover, blood/serum naturally has a basal level of $\mathrm{ABs}$ from immune system cells which arise during regular immune responses $(45,46)$.

Our in-vitro studies validated that selected flow-cytometry assay measures $\mathrm{ABs}$ released to culture supernatants. Additionally, using CNS cell-specific surface markers previously validated in human immunopanning isolation of specific CNS cell-types provided high expectation that enumeration of CNS cell-specific ABs may be of clinical value. Unfortunately, after breaking the diagnostic codes we observed no differences between diagnostic categories and no correlations with any clinical or imaging outcomes of disability, CNS tissue destruction or MS severity. While some may argue that our study was under-powered to detect differences between diagnostic categories, we had good representation of subjects from all four diagnostic categories and found no biologically plausible trends. We concluded that expanding our dataset using the same assay would be futile, as such test could never be applied on a patientlevel and therefore cannot outperform current tests such as NFL.

There are several possible interpretations of our negative results: as cell-surface proteins are often shed during apoptosis (47-49) and changes in cell membrane structure induced by apoptosis increase non-specific binding of antibodies (37-39), accurate determination of the origin of apoptotic bodies using flow cytometry may not be possible. The interference from non-specific binding is supported by the observed overlap of multiple CNS cell-type specific surface markers on the individual ABs. If non-specific antibody binding, rather than shedding of cell-surface markers from apoptotic cells was the main cause of our negative results, then attempting to use alternative reagents for detection of cell-surface molecules, such as DNA-aptamers (50) may be of use. Unfortunately, such alternative reagents are not commercially available for validated CNS cell-surface markers. Flow cytometry may also not be an ideal method for analyzing ABs, as older flow cytometers have low resolution for subcellular particles. Our employment of enhanced gating guided by size beads and validation of our assay in cell-culture supernatants mitigated this impediment.

The fate of ABs after their release from the CNS cells is unknown; while some may be secreted to the CSF via extracellular fluid, others, perhaps most, are likely phagocytosed closer to their origin (51-53). Especially, in the context of pro-inflammatory

\section{REFERENCES}

1. Compston A, Coles A. Multiple sclerosis. Lancet. (2002) 359:1221-31. doi: 10.1016/S0140-6736(02)08220-X environment rich in myeloid cells such as activated microglia and infiltrating macrophages, this local capture of ABs may be much more efficient in MS and OIND controls than in healthy subject, mitigating expected differences between diagnostic categories. Thus, CSF concentrations of ABs may not reliably reflect their CNS origin.

We conclude that measuring $\mathrm{ABs}$ in the CSF using flow cytometry does not provide desired clinical value. We present our negative report in an effort to prevent other investigators from pursuing this path without incorporating substantial technical advancement that may mitigate problems identified in our study. Thus, a need to develop CNS cell-specific biomarkers reflective of neurodegenerative mechanisms associated with CNS diseases remains.

\section{DATA AVAILABILITY STATEMENT}

The flow cytometry data of patients' CSF ABs and their demographic and clinical information are provided in Supplementary Data File 1.

\section{ETHICS STATEMENT}

The studies involving human participants were reviewed and approved by NIH-CNS-IRB. Written informed consent to participate in the study was provided either by participant or by his/her legal guardian/next of kin.

\section{AUTHOR CONTRIBUTIONS}

$\mathrm{BB}$ and RM designed the study. RM, JM, and JP performed the experiments. RM, PW, and $\mathrm{BB}$ analyzed the data. RM wrote the first draft of the manuscript. All authors contributed to manuscript revision, read, and approved the submitted version.

\section{FUNDING}

This study was supported by the intramural research program of the National Institute of Allergy and Infectious Diseases (NIAID, Grant number: NS003055-12) of the National Institutes of Health (NIH).

\section{SUPPLEMENTARY MATERIAL}

The Supplementary Material for this article can be found online at: https://www.frontiersin.org/articles/10.3389/fneur. 2019.01241/full\#supplementary-material

Supplementary Data File 1 | Flow cytometry data for all subjects' CSF samples including their MRI and clinical measures (COMRIS-CTD, EDSS, CombiWISE, MS-DSS, and CombiWISE Slope), clinical diagnosis and demographics (age and gender).

2. Friese MA, Schattling B, Fugger L. Mechanisms of neurodegeneration and axonal dysfunction in multiple sclerosis. Nat Rev Neurol. (2014) 10:225-38. doi: 10.1038/nrneurol. 2014.37 
3. Yilmaz A, Blennow K, Hagberg L, Nilsson S, Price RW, Schouten J, et al. Neurofilament light chain protein as a marker of neuronal injury: review of its use in HIV-1 infection and reference values for HIV-negative controls. Expert Rev Mol Diagn. (2017) 17:761-70. doi: 10.1080/14737159.2017.1341313

4. Khalil M, Teunissen CE, Otto M, Piehl F, Sormani MP, Gattringer T, et al. Neurofilaments as biomarkers in neurological disorders. Nat Rev Neurol. (2018) 14:577-89. doi: 10.1038/s41582-018-0058-z

5. Rissin DM, Kan CW, Campbell TG, Howes SC, Fournier DR, Song L, et al. Single-molecule enzyme-linked immunosorbent assay detects serum proteins at subfemtomolar concentrations. Nat Biotechnol. (2010) 28:595-9. doi: $10.1038 /$ nbt. 1641

6. Kan CW, Rivnak AJ, Campbell TG, Piech T, Rissin DM, Mosl M, et al. Isolation and detection of single molecules on paramagnetic beads using sequential fluid flows in microfabricated polymer array assemblies. Lab Chip. (2012) 12:977-85. doi: 10.1039/C2LC20744C

7. Khalil M, Salzer J. CSF neurofilament light: a universal risk biomarker in multiple sclerosis? Neurology. (2016) 87:1068-9. doi: 10.1212/WNL.0000000000003107

8. Kuhle J, Barro C, Disanto G, Mathias A, Soneson C, Bonnier G, et al. Serum neurofilament light chain in early relapsing remitting MS is increased and correlates with CSF levels and with MRI measures of disease severity. Mult Scler. (2016) 22:1550-9. doi: 10.1177/1352458515623365

9. Kuhle J, Nourbakhsh B, Grant D, Morant S, Barro C, Yaldizli O, et al. Serum neurofilament is associated with progression of brain atrophy and disability in early MS. Neurology. (2017) 88:826-31. doi: 10.1212/WNL.0000000000003653

10. Bhan A, Jacobsen C, Myhr KM, Dalen I, Lode K, Farbu E. Neurofilaments and 10-year follow-up in multiple sclerosis. Mult Scler. (2018) 24:1301-7. doi: 10.1177/1352458518782005

11. Siller N, Kuhle J, Muthuraman M, Barro C, Uphaus T, Groppa S, et al. Serum neurofilament light chain is a biomarker of acute and chronic neuronal damage in early multiple sclerosis. Mult Scler. (2019) 25:678-86. doi: 10.1177/1352458518765666

12. Peterson JW, Bo L, Mork S, Chang A, Trapp BD. Transected neurites, apoptotic neurons, and reduced inflammation in cortical multiple sclerosis lesions. Ann Neurol. (2001) 50:389-400. doi: 10.1002/ana.1123

13. Barnett $\mathrm{MH}$, Prineas JW. Relapsing and remitting multiple sclerosis: pathology of the newly forming lesion. Ann Neurol. (2004) 55:458-68. doi: 10.1002/ana.20016

14. Offen D, Kaye JF, Bernard O, Merims D, Coire CI, Panet H, et al. Mice overexpressing $\mathrm{Bcl}-2$ in their neurons are resistant to myelin oligodendrocyte glycoprotein (MOG)-induced experimental autoimmune encephalomyelitis (EAE). J Mol Neurosci. (2000) 15:167-76. doi: 10.1385/JMN:15:3:167

15. Kerr JF, Wyllie AH, Currie AR. Apoptosis: a basic biological phenomenon with wide-ranging implications in tissue kinetics. Br J Cancer. (1972) 26:23957. doi: 10.1038/bjc.1972.33

16. Akers JC, Gonda D, Kim R, Carter BS, Chen CC. Biogenesis of extracellular vesicles (EV): exosomes, microvesicles, retrovirus-like vesicles, and apoptotic bodies. J Neurooncol. (2013) 113:1-11. doi: 10.1007/s11060-013-1084-8

17. Mallat Z, Hugel B, Ohan J, Leseche G, Freyssinet JM, Tedgui A. Shed membrane microparticles with procoagulant potential in human atherosclerotic plaques: a role for apoptosis in plaque thrombogenicity. Circulation. (1999) 99:348-53. doi: 10.1161/01.CIR.99.3.348

18. Werner N, Wassmann S, Ahlers P, Kosiol S, Nickenig G. Circulating CD31+/annexin $\mathrm{V}+$ apoptotic microparticles correlate with coronary endothelial function in patients with coronary artery disease. Arterioscler Thromb Vasc Biol. (2006) 26:112-6. doi: 10.1161/01.ATV.0000191634.13057.15

19. Lazaro-Ibanez E, Sanz-Garcia A, Visakorpi T, Escobedo-Lucea C, Siljander $\mathrm{P}$, Ayuso-Sacido A, et al. Different gDNA content in the subpopulations of prostate cancer extracellular vesicles: apoptotic bodies, microvesicles, and exosomes. Prostate. (2014) 74:1379-90. doi: 10.1002/pros.22853

20. Perez-Hernandez J, Cortes R. Extracellular vesicles as biomarkers of systemic lupus erythematosus. Dis Markers. (2015) 2015:613536. doi: 10.1155/2015/613536

21. Barbour C, Kosa P, Komori M, Tanigawa M, Masvekar R, Wu T, et al. Molecular-based diagnosis of multiple sclerosis and its progressive stage. Ann Neurol. (2017) 82:795-812. doi: 10.1002/ana.25083
22. Turiak L, Misjak P, Szabo TG, Aradi B, Paloczi K, Ozohanics O, et al. Proteomic characterization of thymocyte-derived microvesicles and apoptotic bodies in BALB/c mice. J Proteomics. (2011) 74:2025-33. doi: 10.1016/j.jprot.2011.05.023

23. Crescitelli R, Lasser C, Szabo TG, Kittel A, Eldh M, Dianzani I, et al. Distinct RNA profiles in subpopulations of extracellular vesicles: apoptotic bodies, microvesicles and exosomes. J Extracell Vesicles. (2013) 2:20677. doi: 10.3402/jev.v2i0.20677

24. Szatanek R, Baran J, Siedlar M, Baj-Krzyworzeka M. Isolation of extracellular vesicles: determining the correct approach (Review). Int J Mol Med. (2015) 36:11-7. doi: 10.3892/ijmm.2015.2194

25. Zhang Y, Chen K, Sloan SA, Bennett ML, Scholze AR, O'Keeffe S, et al. An RNA-sequencing transcriptome and splicing database of glia, neurons, and vascular cells of the cerebral cortex. J Neurosci. (2014) 34:11929-47. doi: 10.1523/JNEUROSCI.1860-14.2014

26. Zhang Y, Sloan SA, Clarke LE, Caneda C, Plaza CA, Blumenthal PD, et al. Purification and characterization of progenitor and mature human astrocytes reveals transcriptional and functional differences with mouse. Neuron. (2016) 89:37-53. doi: 10.1016/j.neuron.2015.11.013

27. Liu L, Shi GP. CD31: beyond a marker for endothelial cells. Cardiovasc Res. (2012) 94:3-5. doi: 10.1093/cvr/cvs108

28. Ziegler-Heitbrock HW, Ulevitch RJ. CD14: cell surface receptor and differentiation marker. Immunol Today. (1993) 14:121-5. doi: 10.1016/0167-5699(93)90212-4

29. Hristov M, Erl W, Linder S, Weber PC. Apoptotic bodies from endothelial cells enhance the number and initiate the differentiation of human endothelial progenitor cells in vitro. Blood. (2004) 104:2761-6. doi: 10.1182/blood-2003-10-3614

30. Polman CH, Reingold SC, Banwell B, Clanet M, Cohen JA, Filippi M, et al. Diagnostic criteria for multiple sclerosis: 2010 revisions to the McDonald criteria. Ann Neurol. (2011) 69:292-302. doi: 10.1002/ana.22366

31. Kosa P, Komori M, Waters R, Wu T, Cortese I, Ohayon J, et al. Novel composite MRI scale correlates highly with disability in multiple sclerosis patients. Mult Scler Relat Disord. (2015) 4:526-35. doi: 10.1016/j.msard.2015.08.009

32. Kurtzke JF. Rating neurologic impairment in multiple sclerosis: an expanded disability status scale (EDSS). Neurology. (1983) 33:1444-52. doi: 10.1212/WNL.33.11.1444

33. Kosa P, Ghazali D, Tanigawa M, Barbour C, Cortese I, Kelley W, et al. Development of a sensitive outcome for economical drug screening for progressive multiple sclerosis treatment. Front Neurol. (2016) 7:131. doi: 10.3389/fneur.2016.00131

34. Weideman AM, Barbour C, Tapia-Maltos MA, Tran T, Jackson K, Kosa P, et al. New multiple sclerosis disease severity scale predicts future accumulation of disability. Front Neurol. (2017) 8:598. doi: 10.3389/fneur.2017.00598

35. Weller RO, Engelhardt B, Phillips MJ. Lymphocyte targeting of the central nervous system: a review of afferent and efferent CNS-immune pathways. Brain Pathol. (1996) 6:275-88. doi: 10.1111/j.1750-3639.1996.tb00855.x

36. Engelhardt B, Carare RO, Bechmann I, Flugel A, Laman JD, Weller RO. Vascular, glial, and lymphatic immune gateways of the central nervous system. Acta Neuropathol. (2016) 132:317-38. doi: 10.1007/s00401-016-1606-5

37. Bailey RW, Nguyen T, Robertson L, Gibbons E, Nelson J, Christensen RE, et al. Sequence of physical changes to the cell membrane during glucocorticoidinduced apoptosis in S49 lymphoma cells. Biophys J. (2009) 96:2709-18. doi: 10.1016/j.bpj.2008.12.3925

38. Gibbons E, Pickett KR, Streeter MC, Warcup AO, Nelson J, Judd AM, et al. Molecular details of membrane fluidity changes during apoptosis and relationship to phospholipase A(2) activity. Biochim Biophys Acta. (2013) 1828:887-95. doi: 10.1016/j.bbamem.2012.08.024

39. Zhang Y, Chen X, Gueydan C, Han J. Plasma membrane changes during programmed cell deaths. Cell Res. (2018) 28:9-21. doi: 10.1038/cr.2017.133

40. Buck D, Hemmer B. Treatment of multiple sclerosis: current concepts and future perspectives. J Neurol. (2011) 258:1747-62. doi: 10.1007/s00415-011-6101-2

41. Garcia-Romero N, Carrion-Navarro J, Esteban-Rubio S, Lazaro-Ibanez E, Peris-Celda M, Alonso MM, et al. DNA sequences within glioma-derived extracellular vesicles can cross the intact blood-brain barrier and be 
detected in peripheral blood of patients. Oncotarget. (2017) 8:1416-28. doi: 10.18632 /oncotarget. 13635

42. Selmaj I, Cichalewska M, Namiecinska M, Galazka G, Horzelski W, Selmaj $\mathrm{KW}$, et al. Global exosome transcriptome profiling reveals biomarkers for multiple sclerosis. Ann Neurol. (2017) 81:703-17. doi: 10.1002/ana.24931

43. Galazka G, Mycko MP, Selmaj I, Raine CS, Selmaj KW. Multiple sclerosis: serum-derived exosomes express myelin proteins. Mult Scler. (2018) 24:44958. doi: 10.1177/1352458517696597

44. Ihara T, Yamamoto T, Sugamata M, Okumura H, Ueno Y. The process of ultrastructural changes from nuclei to apoptotic body. Virchows Arch. (1998) 433:443-7. doi: $10.1007 / \mathrm{s} 004280050272$

45. Caruso S, Poon IKH. Apoptotic cell-derived extracellular vesicles: more than just debris. Front Immunol. (2018) 9:1486. doi: 10.3389/fimmu.2018.01486

46. Xu X, Lai Y, Hua ZC. Apoptosis and apoptotic body: disease message and therapeutic target potentials. Biosci Rep. (2019) 39:BSR20180992. doi: 10.1042/BSR20180992

47. Madge LA, Sierra-Honigmann MR, Pober JS. Apoptosis-inducing agents cause rapid shedding of tumor necrosis factor receptor 1 (TNFR1). A nonpharmacological explanation for inhibition of TNF-mediated activation. J Biol Chem. (1999) 274:13643-9. doi: 10.1074/jbc.274.19.13643

48. Ilan N, Mohsenin A, Cheung L, Madri JA. PECAM-1 shedding during apoptosis generates a membrane-anchored truncated molecule with unique signaling characteristics. FASEB J. (2001) 15:362-72. doi: $10.1096 / f j .00-0372 \mathrm{com}$

49. DeLeo FR. Attractive shedding. Blood. (2007) 110:1711-2. doi: 10.1182/blood-2007-06-096677
50. Giudice V, Biancotto A, Wu Z, Cheung F, Candia J, Fantoni G, et al. Aptamerbased proteomics of serum and plasma in acquired aplastic anemia. Exp Hematol. (2018) 68:38-50. doi: 10.1016/j.exphem.2018.09.008

51. Witting A, Muller P, Herrmann A, Kettenmann H, Nolte C. Phagocytic clearance of apoptotic neurons by Microglia/Brain macrophages in vitro: involvement of lectin-, integrin-, and phosphatidylserine-mediated recognition. J Neurochem. (2000) 75:1060-70. doi: 10.1046/j.1471-4159.2000.0751060.x

52. Takahashi K, Rochford CD, Neumann H. Clearance of apoptotic neurons without inflammation by microglial triggering receptor expressed on myeloid cells-2. J Exp Med. (2005) 201:647-57. doi: 10.1084/jem.20041611

53. Kurant E, Axelrod S, Leaman D, Gaul U. Six-microns-under acts upstream of Draper in the glial phagocytosis of apoptotic neurons. Cell. (2008) 133:498509. doi: $10.1016 /$ j.cell.2008.02.052

Conflict of Interest: The authors declare that the research was conducted in the absence of any commercial or financial relationships that could be construed as a potential conflict of interest.

Copyright (๐ 2019 Masvekar, Mizrahi, Park, Williamson and Bielekova. This is an open-access article distributed under the terms of the Creative Commons Attribution License (CC BY). The use, distribution or reproduction in other forums is permitted, provided the original author(s) and the copyright owner(s) are credited and that the original publication in this journal is cited, in accordance with accepted academic practice. No use, distribution or reproduction is permitted which does not comply with these terms. 